\title{
Impact of Load Behavior on Transient Stability and Power Transfer Limitations
}

\section{Gordon, Mark}

Published in:

IEEE Power Engineering Society General Meeting

Link to article, DOI:

10.1109/PES.2009.5275908

Publication date:

2009

Document Version

Publisher's PDF, also known as Version of record

Link back to DTU Orbit

Citation (APA):

Gordon, M. (2009). Impact of Load Behavior on Transient Stability and Power Transfer Limitations. In IEEE Power Engineering Society General Meeting IEEE. https://doi.org/10.1109/PES.2009.5275908

\section{General rights}

Copyright and moral rights for the publications made accessible in the public portal are retained by the authors and/or other copyright owners and it is a condition of accessing publications that users recognise and abide by the legal requirements associated with these rights.

- Users may download and print one copy of any publication from the public portal for the purpose of private study or research.

- You may not further distribute the material or use it for any profit-making activity or commercial gain

- You may freely distribute the URL identifying the publication in the public portal 


\title{
Impact of Load Behavior on Transient Stability and Power Transfer Limitations
}

\author{
Mark Gordon, Member, IEEE
}

\begin{abstract}
This paper presents utility based load modeling practices and explores the interaction between loads and the power system and the effect of the interaction on transient stability and power transfer limitations. The effect of load composition is investigated at major load centers together with the impact on rotor angle excursions of large scale generators during the transient and post-transient period. Responses of multi-induction motor stalling are also considered for different fault clearances in the system. Findings of the investigations carried out on the Eastern Australian interconnected power systems are presented. A series of examples illustrate the results for which stable and unstable system responses are obtained.
\end{abstract}

Index Terms-Load modeling, Power system transient stability, Interconnected power systems

\section{INTRODUCTION}

$\mathbf{M}$ ODELING the variations of the loads active and reactive power demand, including their voltage characteristics, is an important consideration in stability studies. The dynamic response of power system loads has been widely recognized as an important factor contributing to the overall assessment of power system stability. Furthermore, incorrect load models can cause severe mistakes in determining power system stability margins and damping of oscillations [1]. For example, the system collapse of Tokyo in 1987 was partly due to underestimating the behavior in reactive demand of air conditioning loads. Usually, the power system loads are modeled as constants. Commonly used loads are modeled as constant power, constant impedance and constant current however different load models used for analysis in a variety of power system problems can have significant impact on the overall stability. For example, it has been pointed out in [2]-[5] that constant load models can be inadequate in power system dynamics studies and voltage collapse scenarios whereas in [6], [7] it has been pointed out that the presence of static load component may be more beneficial to stability than the presence of dynamic loads. Research on load composition and modeling still continues to be an important area in power system engineering. Some of the latest results on validation and modeling of composite loads can be found in [8]-[10]. Equally, the importance of load modeling and its influence in system stability studies has been established and documented in [11] and the references therein. The fact that the loads are stochastic, complex and time varying combinations of many different components leads to impracticality or great difficulty in modeling all the devices connected to the power system grid.

M. Gordon is with the Research Center for Electric Technology, DTU Elektro, Technical University of Denmark, DK-2800 Lyngby, Denmark, Email: mag@elektro.dtu.dk
Power system stability studies have traditionally used static load models representing a static relationship between load and voltage as $P_{d}=P_{o}\left(V / V_{o}\right)^{n_{p}} ; Q_{d}=Q_{o}\left(V / V_{o}\right)^{n_{q}}$ where $P_{o}, Q_{o}$ and $V_{o}$ are nominal active, reactive power and voltage at the load bus, $n_{p}$ and $n_{q}$ are voltage exponents for real and reactive powers. However, the majority of power system loads have dynamic characteristics which may include on-load tap changing transformers, induction motors, thermostats, feeder voltage regulators, voltage controlled feeder capacitors etc. It is also known that majority (greater that 60\%) of power system loads are induction motors, whose impact on general load behavior must be taken into account [12], [13]. The problem of modeling the dynamic characteristics of loads is that it is difficult to collect detailed load composition data. Generally, only the aggregate behavior is required for power system stability studies rather than a whole collection of individual component behaviors. The two main approaches to load modeling are component and a measurement based approach. The component based approach builds up the aggregate load model with static and dynamic behavior of all individual components at a particular load bus. However, the survey of individual load characteristics can be a difficult task since there is no uniformity in electrical appliance ratings, and, problems can even occur when combining models of the same type, such as induction motors. The measurement based approach is a system identification problem generally concerned with frequency and time domain methods. The vast majority of methods used in industry are time domain methods, which involve the placement of sensors and measurement equipment to estimate the appropriate model structure and its parameters. Furthermore, there are always continual variations in the load itself and small transient effects that can complicate the interpretation of measured results. A good way to identify models over a wider range of system conditions is to measure load behavior during large disturbances. The main drawback is the difficulty in making voltage changes in excess of $10 \%$ under normal operating conditions, while the interest is often in a much larger range. Similarly, frequency deviations can be hard to make except by special isolation of typical loads [12]. Beside all the difficulties, many measurements in different power systems have been made to establish load models for different purposes. As an example, the forms of response of different loads to a voltage step have been discussed in a number of reports, see [6], [14]-[16]. Relating in part to those measurements, different load models have since been proposed to capture the characteristics of the power system for the type of situation being analyzed.

This paper is motivated by the need for the improved load modeling strategies with the revision of industrial practical 
guidelines in applying load models to power system stability studies. Transient stability study is assessed in order to analyze system sensitivity and determine safe transfer limits under the most critical fault conditions. Such a fault may be a trip of a large generator, trip of a load, transmission line fault on a critical location etc. The paper present findings of the investigations carried out on the Australian interconnected power systems grid considering the load behavior of static and composite load models, including the analysis of induction motor stability in response to system disturbances.

\section{On LoAd Modeling In POWER Systems}

Use of appropriate load models in power system studies is essential and an integral part in system planning and operation. The impacts of different load models in stability studies can be significant. Some industry practices are based on models yielding conservative results in order to provide a safety margin in the system design or operating limits. Use of optimistic loads can lead to operation of system beyond actual limits and making it easily exposed to major collapses. Selecting the optimistic model can be a dangerous approach because it may not always be possible to assume that the model would apply to all parts in the system. Therefore a careful approach must be considered, where both conservative models and those giving closer to a limit operation have to be analyzed and tested. It may not be always obvious when the load characteristics are important or when loads can greatly influence stability of the system. A good approach to assess sensitivity to load characteristics is to make comparative simulations with a range of load models.

\section{A. Static Load Models}

This model expresses active and reactive powers at any instant of time as functions of the bus voltage and frequency at the same instant. The voltage dependency of load characteristics is represented by well known exponential $n_{p}$ and $n_{q}$ indices (exponents). By setting these load indices to 0,1 , or 2, the load model can be represented by constant power, constant current, or constant impedance, respectively. Static load models are also called non-linear load models. The work presented in this paper concerns load indices which are varied across the entire Australian system, and at particular major loads across the state of NSW (New South Wales), in order to analyze the effects of system responses for the assessment of transient stability capability. A direct comparison to system responses using composite loads is analyzed as well.

\section{B. Dynamic Load Models}

This model expresses active and reactive powers at any instant of time as a function of voltage and frequency at past instants of time and, usually, including the present instant. In other word these models account for dynamic characteristics of loads. The most attributable dynamic aspect of loads comes from motors. Other dynamic aspects in load models that require attention include: discharge lamps, operation of protective relays, thermostatic control of loads, response of under load tap changing on distribution transformers, regulators, capacitor banks etc.
TABLE I

InduCtion Motor PARAMETERs, IEEE TyPe 7 (LARGE DistURBANCE), IEEE TYPE 6 (VOLTAGE FLUCTUATIONS)

\begin{tabular}{|l|c|c|}
\hline Description & IEEE Type 7 & IEEE Type 6 \\
\hline Motor Load Fraction & 0.5 & 0.5 \\
Motor Load Factor & 0.55 & 0.6 \\
Inertia Constant & $0.3 \mathrm{sec}$ & $0.42 \mathrm{sec}$ \\
$R_{s}$ & $0.064 \mathrm{pu}$ & $0.034 \mathrm{pu}$ \\
$X_{s}$ & $0.091 \mathrm{pu}$ & $0.094 \mathrm{pu}$ \\
$X_{m}$ & $2.23 \mathrm{pu}$ & $2.8 \mathrm{pu}$ \\
$R_{r}$ & $0.059 \mathrm{pu}$ & $0.048 \mathrm{pu}$ \\
$X_{r}$ & $0.178 \mathrm{pu}$ & $0.163 \mathrm{pu}$ \\
\hline
\end{tabular}

\section{Composite Load Models}

A composite load model developed by Transmission System Operators in Australia is consistent with the IEEE guidelines, which include explicit representation of motor and resistive components. A composite load model refers to a load that behaves as a constant impedance, power, or current and in addition to this, there is a part of a load representing an aggregate average induction motor which exhibits dynamic characteristics. Dynamic parameters of induction motors used in composite load models are specified according to IEEE guidelines for use in large disturbance studies (transient stability), i.e. IEEE Type 7 motor parameter designation, whereas the IEEE Type 6 model is used for studies involving small signal voltage changes. Both of these models are shown in Table I. Based on this representation, initial utility studies involved variations in motor load fractions with remaining static load model with indices $n_{p}=1$ and $n_{q}=3$ across PQ buses in Australia. Additional refinements were incorporated based on research analysis applied in NSW. This resulted in inclusion of distribution system and replacement of the static reactive term with: a shunt admittance term, representing inductive loads and capacitors; and, representation of transformer, motor, and other saturation effects. As a result new composite load model was developed [17], represented by: a step down transformer, averaged induction motor component, resistive load component, shunt capacitor banks, and saturation of magnetic parts of motors and transformers. The components assigned to this model are:

- Effective transformer tap ratio: value is chosen to ensure that the initial steady state value on the composite bus is regulated to $1 \mathrm{pu}$.

- Effective transformer series reactance: is the total series reactance between HV bus and the effective load bus

- Equivalent induction motor model: is the aggregate of all the induction motors supplied from the HV bus

- Magnetic saturation branch: variation of voltage of the excitation current of shunt elements (motors and transformers)

- Constant resistance branch: resistance is chosen to consume the P load that is not absorbed by induction motors

- Shunt capacitive branch: value is chosen so that the total $\mathrm{Q}$ at HV bus is the value assigned in the load flow

This model is analogous to composite load model described in literature [18], except for some details in complexity of the model which have been left out or combined in the averaged aggregate composite form. 
TABLE II

LOAD MODEL REPRESENTATION FOR PLANNING STUDIES

\begin{tabular}{|l|c|}
\hline Region & Load Representation \\
\hline New South Wales & Composite model with available parameters \\
Queensland & Composite and Static Load Model \\
South Australia & Static Model \\
Tasmania & Static Model \\
Victoria & Static Model \\
\hline
\end{tabular}

\section{Interim Load Modeling}

Much work has been done on generation and corresponding transient stability transfer limit studies, where simple machine modeling and constant impedance load models were used. Since commissioning of QNI (Queensland to NSW 600km interconnector) increased attention has been paid in gathering information to develop dynamic load models, so that transfer limits can be obtained with some confidence. However, load models would typically vary with the time of the year and also increase computational complexity in system analysis. Due to system interconnections across the eastern Australian grid, higher transfer limits are desired to satisfy increasing demands in other states. Index load models can yield limits, which are lower or close to limits provided by models incorporating dynamic characteristics of loads. In some cases a safety margin of few hundred MW can be needed, therefore index based load models seem to add difficulty in defining NSW export limits [17]. Differences produced by static and dynamic loads have resulted in developed composite load model. This model, applied in Section IV, has been shown to give good responses during and immediately after severe system disturbances. Disadvantages associated with composite load model development can be increased complexity in simulations and accurate prediction of load variations. Full development of parameters is therefore needed for simulation accuracy. In the meantime, use of both static and composite load models is recommended. Where uncertainties of both models have to be considered, it is a common practice to choose a model that yields pessimistic results, or in the case of transfer limitations, the one that gives the lowest limit. Example studied in this paper is transfer limit across QNI. In general, recommendations are set to: apply the static load model if it gives transfer limits equal to or less than the composite load model, and, if the static model leads to conservative results, then the use of composite load model in all studies is expected. Load models currently in use by different regions are given in Table II.

In this study, both static and composite load models and their behavior in disturbance situations is analyzed and presented. Load characteristics have been found to be important in transfer limits of exporting region.

\section{E. Load Monitoring}

A number of load monitors has been installed in NSW at few 330/132kV load centers, for example Sydney North, Sydney South, Sydney East, Sydney West, Beaconsfield West, Dapto and Canberra. They are intended for monitoring and collecting dynamic load characteristics during system disturbances in order to allow for derivation of detailed load models for different load group compositions. The most useful data

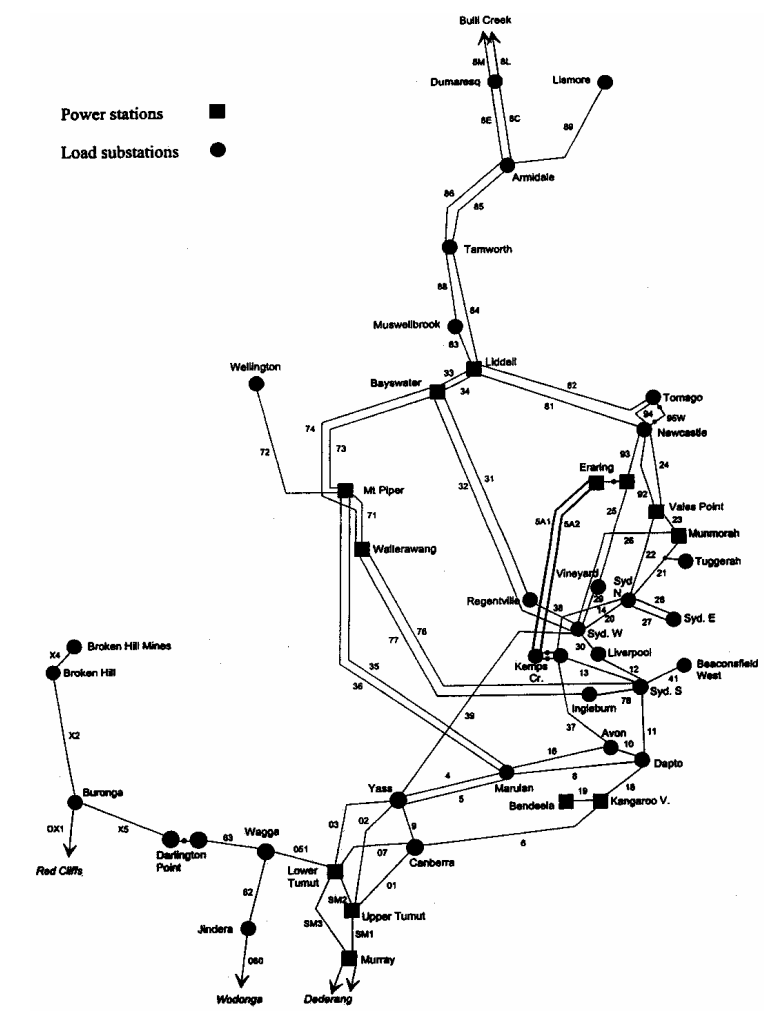

Fig. 1. NSW Main Transmission System

response has been recorded at Sydney West for different faults in the system. Another significant work in the area of load behavior has been a detailed study of Canberra load. However, in order for any transient stability studies to proceed in a short term, an interim load approach, Table II is presently applied.

\section{Power System Model}

In the analysis of the system, synchronous generators operate and are part of a large interconnected system through connections from Queensland to New South Wales to Victoria and to South Australia. The main NSW transmission network considered in this paper is given in Fig.1 A complete model used in simulations of the interconnected Eastern Australian power system can be obtained from NEMMCO (National Electricity Market Management Company), see [19]. NSW and Victoria have been interconnected since 1959 via the Snowy mountains scheme. Both systems extended their transmission systems to Snowy for this interconnector to take place [20]. The connections were then extended to South Australia in 1990 via a double circuit $275 \mathrm{kV}$ line. When interconnections were first established, each of the associated power system utilities had sufficient generating resources to support self sufficient operation of networks imposed by load demands. The main characteristic of interconnections is power transmission in larger or sufficient quantities to other states, for greater distances and longer periods of time. As a result, the Eastern Australian interconnection was extended through the construction of a $600 \mathrm{~km}$ QNI link, commissioned in 2001. Following up extensive post-commissioning testing, the transfer capacity is now rated to be up to $400 \mathrm{MW}$ in 


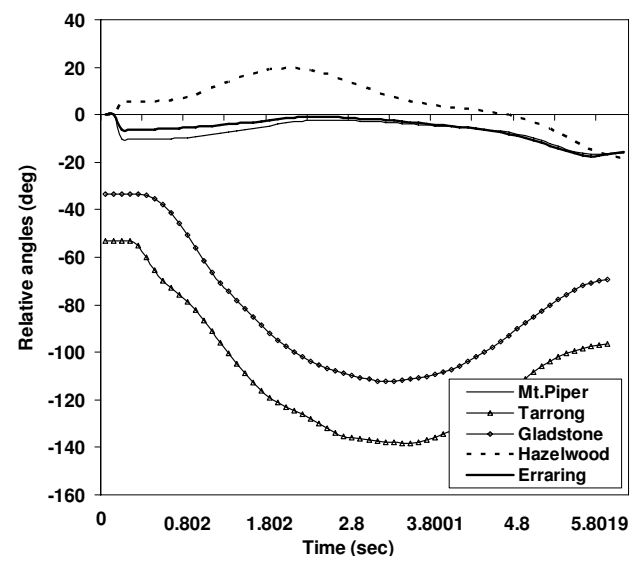

Fig. 2. First Swing Stable Stability Responses with static loads, $n_{p}=1$, $n_{q}=3,460 \mathrm{MW}$ power transfer over QNI

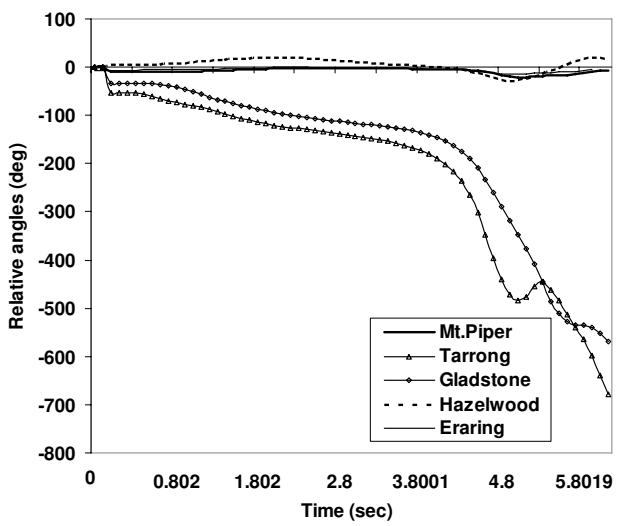

Fig. 3. Loss of Synchronism with static loads, $n_{p}=1, n_{q}=3$, 469MW power transfer over QNI

the northerly direction (QNI export) and up to 1,078 MW in the southerly direction (QNI Import). The main factors determining transfer capability are: transient stability, thermal rating of lines and transformers, voltage stability and system damping. The capability is dependent on the load levels at supply points and the distribution of generation across the interconnected system. With the evolution of interconnections between the states of Australia, a severe fault on critical locations can cause serious effects to neighboring power system grids. Transient stability study is used to determine, among the other factors, transfer limits across these interconnections. The analysis undertaken examines conditions on QNI, for a typical summer load data under a 480MW power export to QLD, when a serious disturbance is imposed on the system. For transient stability analysis, the most critical disturbance is usually the trip of a large generating unit or a severe 2 phase to Earth fault on the $330 \mathrm{kV}$ network in NSW. For this purpose we consider a trip of a Tarong generator in Queensland and a fault on a $330 \mathrm{kV}$ line in NSW, such as Liddell-Bayswater fault. The severity of load behavior at particular load centers is also addressed in the paper for fault locations throughout the NSW system, for which the results are presented Section IV. A graphical display of system disturbances using the TSTAB modeled system is presented. The package incorporates major parts which are load flow program, fault calculation, transient

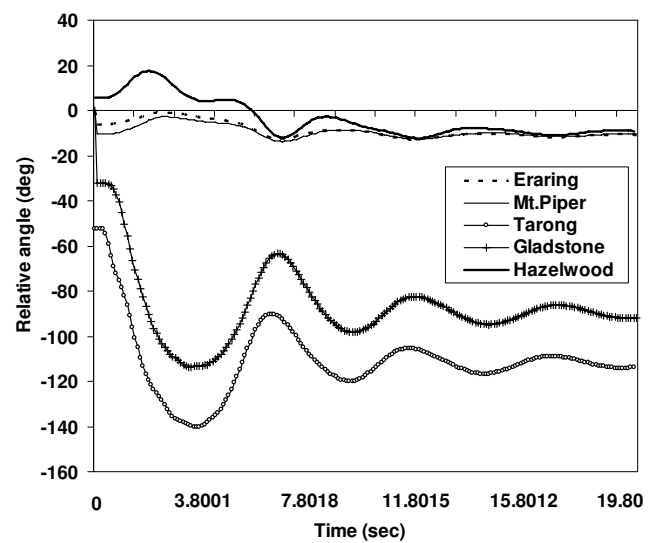

Fig. 4. Transient Stability Responses, $n_{p}=2, n_{q}=2$

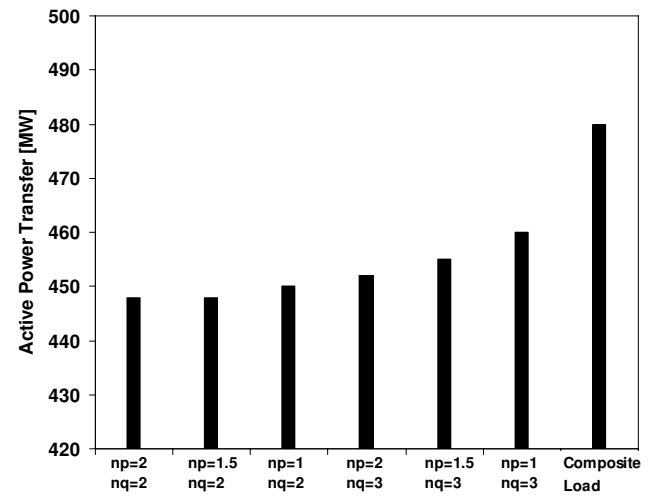

Fig. 5. QNI Transfer Capabilities due to Static and Composite Load Models

simulation program, dynamics characteristics, and a plotting program. Time domain approach is used to visually determine system stability, in this case observation of swing curves for various generators and locations. The transient behavior of power system is modeled by a set of non linear differential equations and based on the implicit integration method used to determine time domain swing responses.

\section{Results I: Static And Composite LoAds}

\section{A. Transient Stability Capability with Static and Composite} Load Models

Tests carried out in this simulation examine and determine export/import limits on QNI using static and composite load model structures modeled at major load centers throughout Australia. Analysis is based on a typical summer season data with 480MW export capability over QNI, with the system flow specification given in Table III.

TABLE III

Snapshot of Pre-Disturbance System Flows

\begin{tabular}{|l|c|c|}
\hline Region & Demand (MW) & Export \\
\hline NSW & 9993 & -598 \\
VIC & 6683 & 600 \\
SA & 2582 & -500 \\
QLD & 6127 & -480 \\
\hline
\end{tabular}

The worst case fault considered is a trip of a generating unit in Queensland. Results are shown in Fig.2-Fig.5. 

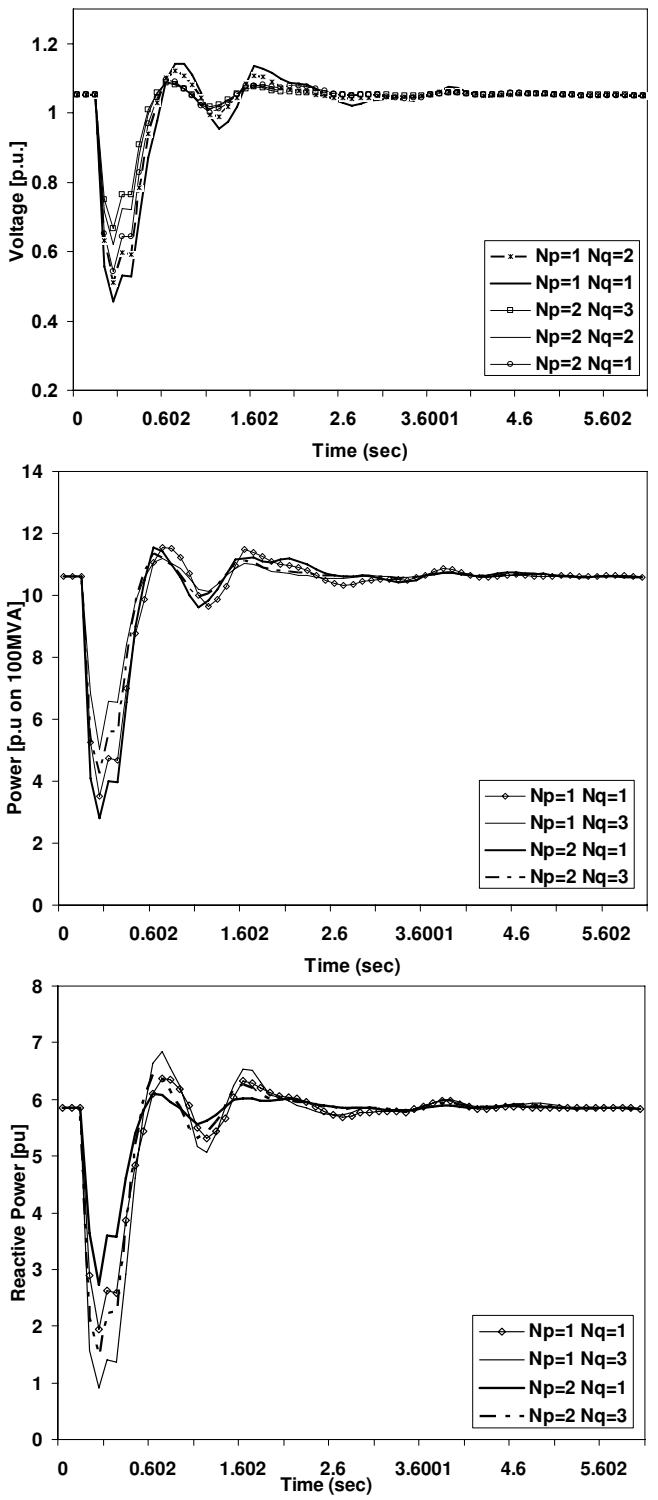

Fig. 6. Impact of static load models on voltage, active power and reactive power responses at Sydney West Substation

Fig.2 and Fig.3 show excursions of rotor angles for machines in Queensland against machines in New South Wales and Victoria. It has been found that the use of $n_{p}=1$ and $n_{q}=3$ load exponents results in reduction of transfer limits, from initially proposed 480MW (for composite loads) to around 460MW. Fig.3 shows unstable system responses for transfers of $469 \mathrm{MW}$, being the point of instability for this type of a static load model. When there is a loss of synchronism, or the machine falls out of step, the machine rotor accelerates or decelerates and the poles slip out of synchronism. The slip between rotating stator field and the rotor field leads to large variations in output power, current, and voltage. In practice, this would require protection system to isolate the unstable machine from the rest of the system. Fig.4 shows an example of system responses up to a simulated period of approximately 1000 cycles. Fig.5 shows a summary of transfer capabilities with different load models. While the concern of
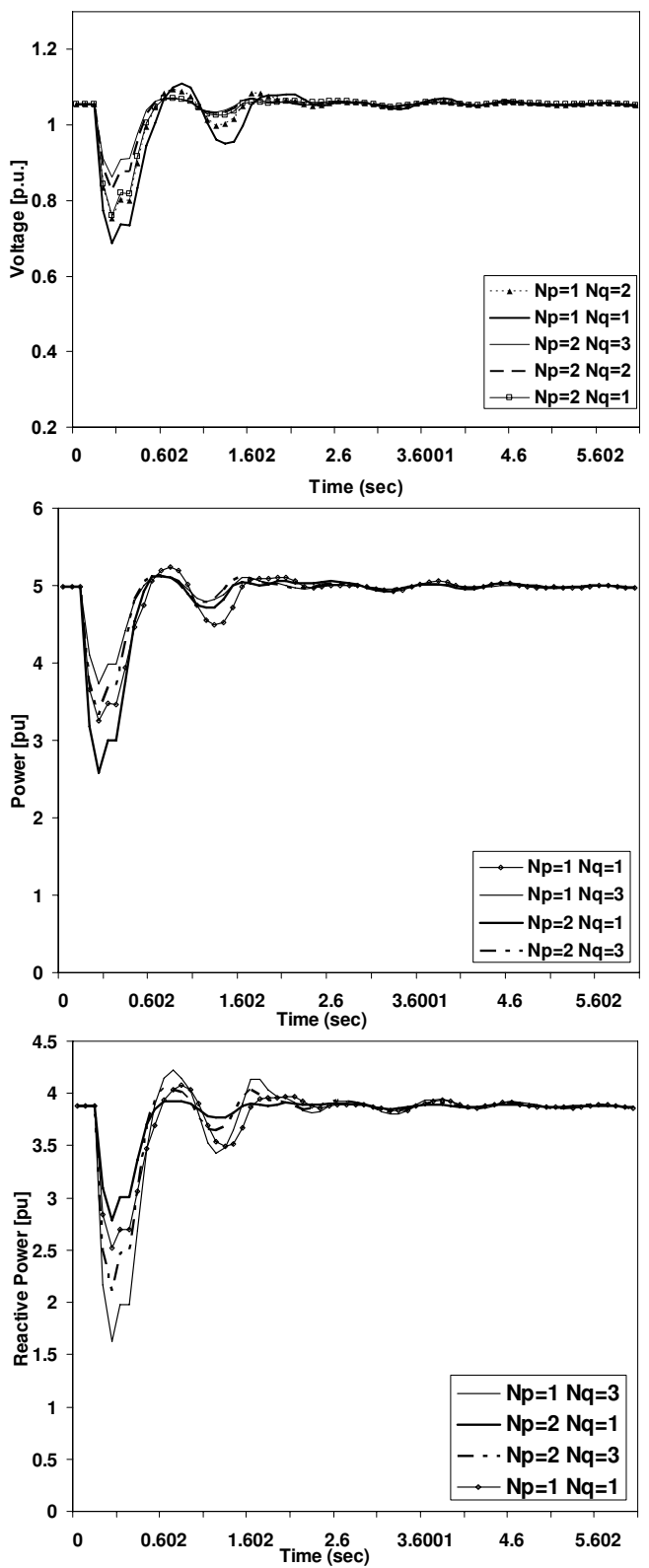

Fig. 7. Impact of static load models on voltage, active power and reactive power responses at Canberra Substation

the analysis has been to vary indices across the range from 1 to 3 , the TSTAB simulation package was not able to converge the network for load parameters below the value of 1 . The values of 0 , i.e. constant power component, and the values of 0.5 for $n_{p}$ did not converge into a feasible system solution.

\section{B. Load Center Responses}

Voltage, active and reactive power profiles are shown in Fig.6 and Fig.7 for major load centers in NSW as a result of a two-phase to Earth fault on a Bayswater-Liddell circuit. For the test cases considered the following can be observed:

- Voltage responses have indicated significant transient voltage drop profiles with $n_{p}=1, n_{q}=1$ and least with $n_{p}=2, n_{q}=3$ static load exponents. 


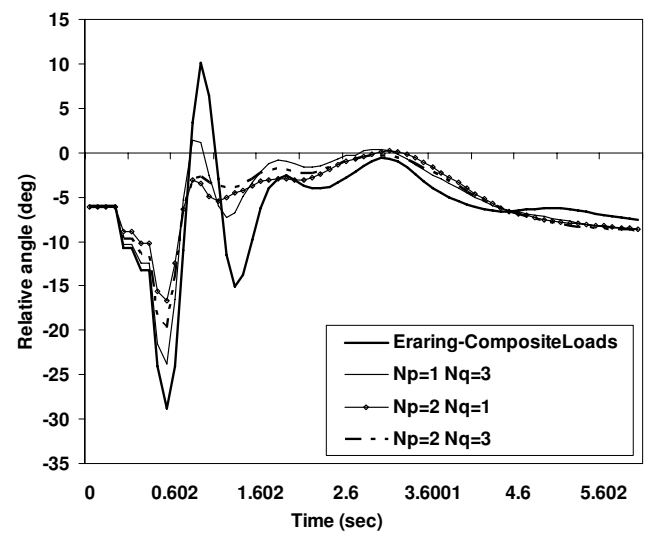

Fig. 8. Impact of static and composite load models at Eraring Power Station

- Active power responses have indicated power drops with $n_{p}=2, n_{q}=1$ and least with $n_{p}=1, n_{q}=3$ static load exponents.

- Reactive power responses have indicated power drops with $n_{p}=1, n_{q}=3$ and least with $n_{p}=2, n_{q}=1$ static load exponents, i.e.opposite to active power profiles.

In general it can be concluded that system sensitivity to active and reactive load voltage exponents could vary for different system configurations and different locations of the load. As it has been pointed out in [11] nonlinear static loads may be either stabilizing or destabilizing and there is no single load characteristic that could lead to defined system responses, instead specific load models have to be developed for specific types of studies in different power systems.

\section{Generator Responses}

The impact of static and composite load models on generator transient stability is shown in Fig.8 and Fig.9. A two-phase to earth fault between Liddell and Bayswater is considered. Results indicated that Eraring rotor angle displacements are more significant in the case of a power system modeled with composite load structure, while responses from Loy Yang generator exhibit similarities in excursions for both composite and static modeled PQ buses in the network. The analysis of generator responses needs to consider appropriate load model structures, together with the location and duration of system disturbances. In some parts of the network, generator responses may be negligibly different with respect to load indices while certain generators could experience quite severe system oscillations. In general such responses would be defined by generator parameters, system conditions and network configuration under particular study.

\section{Results II: Stability of Induction Motors}

An important aspect in stability question of induction motors is whether motors will re-accelerate or stall when subjected to a fault in the HV system resulting in a severe voltage depression for a short period until the fault is cleared. Motor and shaft load inertia, contactor hold in characteristics, and motor electrical parameters such as rotor circuit time constant can be as important as the stiffness of the system

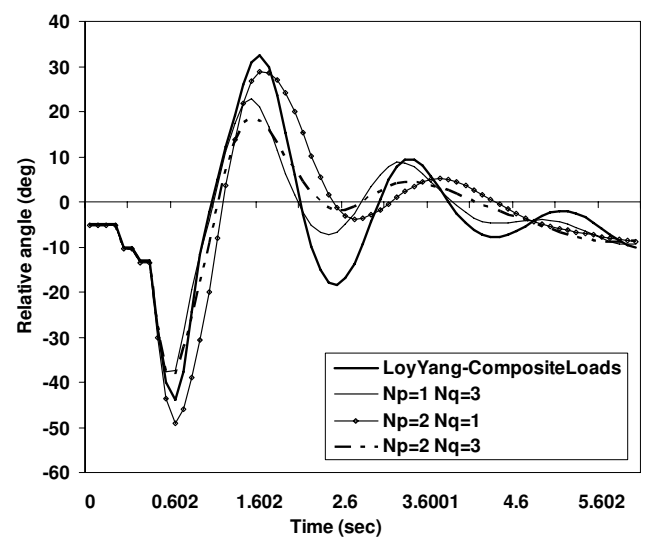

Fig. 9. Impact of static and composite load models at Loy Yang Power Station

[13]. At some specified voltage levels (below 85 to $90 \%$ of the nominal range), some induction motors may stall and draw high reactive current [18]. This in turn can bring voltages down even further. Usually, in practice industrial and commercial motors are controlled by magnetically held contactors, and the voltage drop can cause many motors to be dropped out, and then restored to service again. It can be said that motors draw more or less constant power until a limit is reached, at which point motors will start stalling. Instability of motors, especially of induction motors is generally perceived as voltage instability. It has to be noted that motor instability is different from voltage instability. For a given system voltage there is a maximum torque that an induction motor can develop. If the load torque exceeds this due to an increase in the load or due to a low system voltage for an example, the motor would stall and reduce the system voltage further [7]. This can also lead to stalling of motors across the system, thereby giving potential rise to a cascading system collapse. If the system load is composed predominantly of motor loads, and the stability of induction motors is questionable, it is necessary to consider both large and small disturbances. It is therefore of importance to consider the stability of composite loads which normally include a large proportion of induction motors. Current models incorporated into TSTAB are based on the assumption that $50 \%$ of the power is absorbed by induction motors at load centers. This paper examines whether motors will re-accelerate or stall following fault clearing. The case is based on winter (high) demand data with export limit to QLD at 510MW, being very close to limit of instability. The fault duration on Liddell-Bayswater link (2-phase to Earth fault) is extended and thereafter deceleration of induction motors is traced in order to determine if re-acceleration or stalling occurs. There are some studies indicating that there is a possibility of the induction motor component of the composite load model to stall in weak parts of the system after a voltage depression caused by a severe fault, [17]. In the case of this occurrence, it would require consideration of which motors should be disconnected from the system. However, as discussed in Section II this once again relates to a difficulty in obtaining detailed parameters of load composition. 


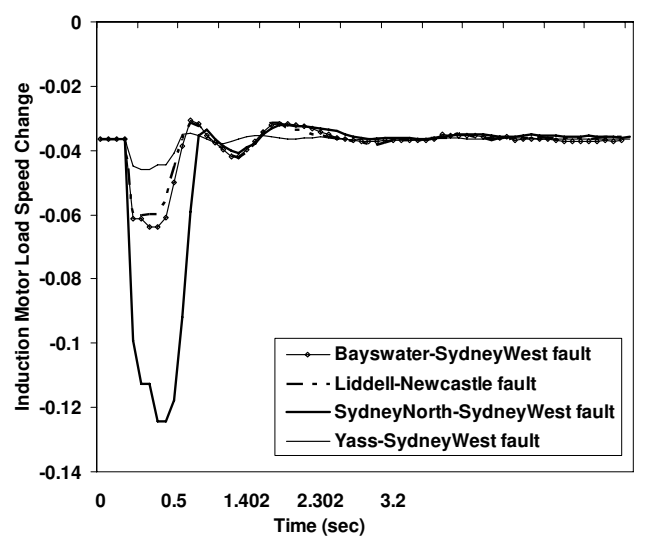

Fig. 10. Induction Motor Speed Changes at Sydney West for different fault locations

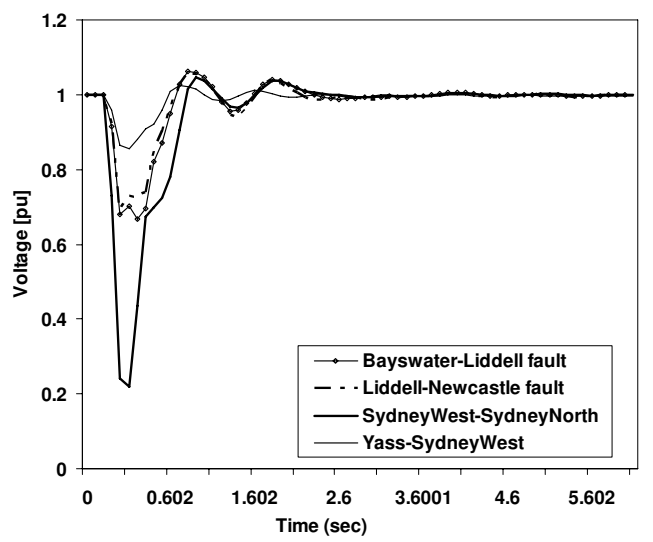

Fig. 11. Voltage Responses at Sydney West for different fault locations

\section{A. Impact of Fault Locations on Induction Motor Responses}

This study examines and compares induction motor load responses at a major load bus in NSW, subject to application of different fault locations across the network. The recorded responses at Sydney West are shown in Fig10 and Fig11. Results indicate that induction motors were able to re-accelerate due to a power system disturbance that caused voltage at the supply point to vary considerably for a Sydney West-Sydney North two-phase to Earth fault.

\section{B. Impact of Fault Duration on Induction Motor Responses}

This study concerns if instability can be traced to motor stalling. This study examines whether motors at a major load centers reaccelerate or stall following extended fault clearing on a Liddell-Bayswater $330 \mathrm{kV}$ circuit. The standard clearing times specified by this fault are set to $4-5.5$ cycles, i.e. circuit breakers open at 4 and 5.5 cycles. Power system is considered to be at its operating limit prior to fault application. Result is shown in Fig.12 and Fig.13 for faults cleared in 4-5.5 and 5-6.5 cycles. From Fig. 12 we can see that the most prominent motor deceleration occurs at Canberra load. Instability in motor speeds occur upon the extension of Liddell-Bayswater fault, shown in Fig.13. It can be seen that motor load at Canberra bus decelerates and motor loads at Newcastle and Sydney West accelerate. This simulation resulted in transient system

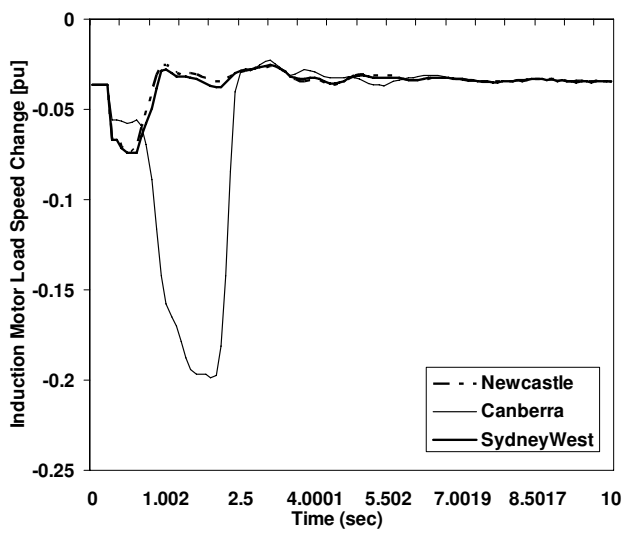

Fig. 12. Induction Motor Speed Changes at three major load centers, fault cleared in 4-5.5 cycles (Stable Case)

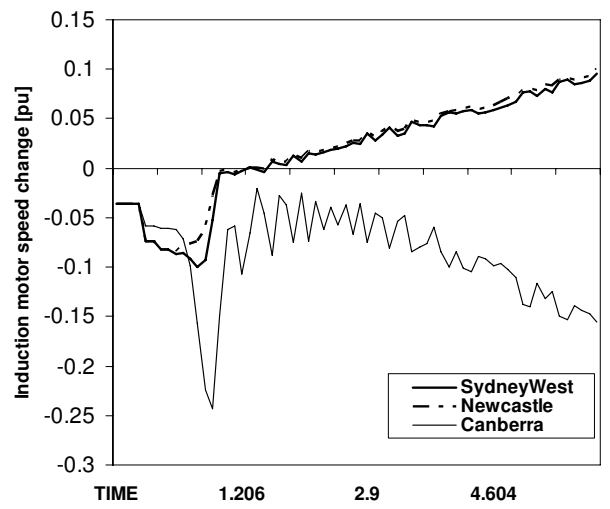

Fig. 13. Induction Motor Speed Changes at three major load centers, fault cleared in 5-6.5 cycles (Unstable Case)

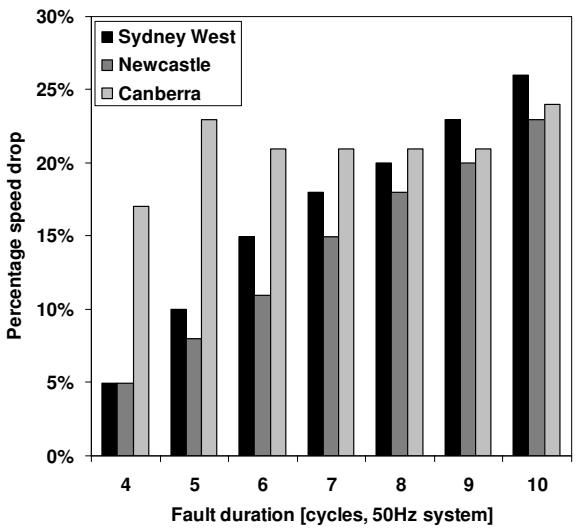

Fig. 14. Induction motors speed drop at three locations as a result of extended fault duration on the Liddell-Bayswater link

separation between New South Wales and Queensland. Fig.14 shows a summary of induction motors speed changes at three major load centers as a result of extended fault duration on the Liddell-Bayswater link. It has been pointed out in [21] that motor stalling can be avoided by capacitor switching, since the capacitor compensated network is able to deliver a higher electrical torque. This multi-load case has illustrated the importance of induction motor loads and their effect in system stability and behavior of motor load systems. 


\section{FUTURE WORK}

There is still considerable progress to be made in understanding load characteristics and methods for determining improved load models. Number of areas where further development is needed, may include:

- Methods and equipment for measurements of load characteristics.

- Enhancement in dynamic performance analysis, including discharge lighting, low voltage motor behavior, long term dynamics, thermostatic type loads etc.

- Improved understanding and modeling of the effect of sub-transmission and distribution networks

- Prediction based procedures for modeling the weather impacts, daily-seasonal and other factors.

\section{CONCLUSIONS}

It has been shown that load modeling has a significant effect on power system dynamic analysis. Assessing critical load models has been found essential in obtaining the accuracy of power system simulation and analysis. The performance of static and composite load models is compared on a large interconnected Eastern Australian power system. It is shown that when static and composite load model characteristics are taken into consideration, large disturbance transient stability is obtained by imposing different reduction on power transfer limits across the major $330 \mathrm{kV}$ interconnector. The effect of load composition is investigated at major load centers and for excursions of large scale generators during the transient and post transient period. The effect of induction motor deceleration and acceleration has been shown for various system faults and different fault clearing times. Results have been shown for stable and unstable system response for different load models and network conditions.

\section{ACKNOWLEDGMent}

The author would like to thank TransGrid for the support, help and provision of resources in making this work possible.

\section{REFERENCES}

[1] Y. V. Makarov, V. A. Maslenikov, and D. J. Hill, "Revealing loads having the biggest influence on power system small disturbance stability," IEEE Transactions on Power Systems, vol. 11, no. 4, Nov 1996.

[2] I. A. Hiskens and D. J. Hill, "Dynamic analysis of voltage collapse in power systems," IEEE Conf. on Decision and Control, pp. 2904-2909, Dec 1992.

[3] I. A. Hiskens and J. V. Milanovic, "Locating dynamic loads which significantly influence damping," IEEE Transactions on Power Systems, vol. 12, no. 1, Feb 1997.
[4] J. V. Milanovic and I. A. Hiskens, "Oscillatory interaction between synchronous generator and local voltage dependent load," IEE Generation, Tranmission and Distribution, vol. 5, pp. 437-480, Sep 1995.

[5] I. Hiskens and D. J. Hill, "Energy functions, transient stability and voltage behaviour in power systems with nonlinear loads," IEEE Transactions on Power Systems, vol. 4, no. 4, Oct 1989.

[6] M. M. Begovic and R. Q. Mills, "Load identification and voltage stability monitoring," IEEE Trans. on Power Systems, vol. 10, no. 1, Feb 1995.

[7] M. K. Pal, "Voltage stability conditions considering load characteristics," IEEE Trans. on Power Systems, vol. 7, no. 1, pp. 243-249, Feb 1992.

[8] H. Renmu, M. Jin, and D. J. Hill, "Composite load modeling via measurement approach," IEEE Trans. on Power Systems, vol. 21, no. 2, May 2006.

[9] M. Jin, H. Renmu, and D. J. Hill, "Load modeling by finding support vectors of load data from field measurements," IEEE Trans. on Power Systems, vol. 21, no. 2, May 2006.

[10] J. Ma, D. Han, R. He, Z. Y. Dong, and D. J. Hill, "Reducing identified parameters of measurement-based composite load model," IEEE Trans. on Power System, vol. 23, no. 1, pp. 76-83, Feb 2008.

[11] J. V. Milanovic, "The influence of loads on power system electromechanical oscillations," PhD Thesis, Newcastle University, Australia, 1996.

[12] C.Concordia and S. Ihara, "Load representation in power stability studies," IEEE Trans. on Power Apparatus and Systems, vol. 101, no. 4 April 1982.

[13] IEEE Task Force on Load Representation for Dynamic Performance, Load Representation for Dynamic Performance Analysis, IEEE Transactions on Power Systems, vol. 8, no. 2, May 1993.

[14] A. Dweyer, R. E. Nielsen, J. Stangl, and N. S. Markushevich, "Load to voltage dependancy tests at bc hydro," IEEE Trans. on Power Systems, vol. 10, no. 2, pp. 709-715, 1995.

[15] D. Karlsson and D. J. Hill, "Modelling and identification of nonlinear dynamic loads in power systems," IEEE Trans. on Power Systems, vol. 9, no. 1, 1994.

[16] S. A. Y. Sabir and D. C. Lee, "Dynamic load models derived from data acquired during system transients," IEEE Trans. on Power Apparatus and Systems, vol. 101, no. 9, pp. 3365-3372, 1982.

[17] Five State Plant Modelling Working Group, TransGrid, Australia, vol. 1, March 1999.

[18] P. Kundur, Power System Stability and Control, The EPRI Power System Engineering Series, McGraw-Hill, Inc 1993.

[19] NEMMCO, "2008 Statement of Opportunities for the National Electricity Market," NEMMCO Australia, www.nemmco.com.au, ISSN 14439050, 2008.

[20] C. J. Parker, A. Manglick, and W. Grainger, "Network and interconnection planning in the Australian market environment," CIGRE Regional Conference, Melbourne, Australia, Oct 1997.

[21] D. H. Popovic, I. A. Hiskens, and D. J. Hill, "Stability analysis of induction motor networks," International Journal of Electrical Power and Energy Systems, vol. 20, no. 7, pp. 475-487, 1998.

Mark Gordon received the $\mathrm{BE}$ (Hons) and the $\mathrm{PhD}$ in electrical engineering from The University of Sydney, Australia, in 2003 and 2007, respectively. Currently he is an Assistant Professor at the Research Center for Electric Technology, Technical University of Denmark. His research interests include power system modeling, stability and control. 